\title{
AVALIAÇÃO DO DESEMPENHO DE EDIFÍCIOS VERTICAIS DE HIS NA CIDADE DE SOROCABA-SP
}

VISBQP

UBERLÂNDIA 2019

\author{
MARTINS, Natália Costa \\ Faculdade de Arquitetura e Urbanismo da Universidade de São Paulo, e-mail: \\ nataliacmartins@usp.br \\ OLIVEIRA, Fabiana Lopes de \\ Faculdade de Arquitetura e Urbanismo da Universidade de São Paulo, e-mail: \\ floliveira@usp.br
}

\begin{abstract}
RESUMO
No Brasil, os sistemas construtivos viabilizados para Habitação de Interesse Social (HIS) eram avaliados somente pelos custos iniciais. Não eram computados os custos de operação e manutenção, relegando a segundo plano, a preocupação com os aspectos de durabilidade, vida útil dos edifícios e, principalmente, a satisfação dos usuários. A produção dessas habitações em larga escala reflete a falta de qualidade projetual e executiva destes edifícios. Porém, com o advento da NBR 15575:2013, esse cenário mudou e a avaliação de desempenho tornou-se prática importante. $\mathrm{O}$ presente artigo, produto de dissertação de Mestrado, apresentará dois estudos de caso, de condomínios construídos no Programa Minha Casa Minha Vida (PMCMV) na cidade de Sorocaba/SP, entre os anos de 2009 a 2015, com objetivo de analisar 0 cumprimento de critérios e requisitos de desempenho de suas moradias baseados na NBR 15575:2013. Para isso, utilizar-se-á parte dos procedimentos metodológicos para Avaliação Pós Ocupação (APO) desenvolvida no projeto intitulado "Desenvolvimento de métodos e metodologias para avaliação de desempenho de tecnologias inovadoras no âmbito do Sistema Nacional de Avaliação Técnica". Pretende-se então, criar parâmetros projetuais e construtivos para futuras HIS da cidade de Sorocaba tendo o desempenho como parâmetro de qualidade e satisfação do usuário.
\end{abstract}

Palavras-chave: APO, Desempenho, Habitação, HIS.

\begin{abstract}
In Brazil, the constructive systems made feasible for Housing of Social Interest (HIS) were evaluated only minding their initial costs. The costs of operation and maintenance were not computed, relegating the proper concern with aspects such as the durability and the safety life of the buildings and, mainly, the satisfaction of the users into second place. The production of these large-scale housing projects reflects the lack of design and executive quality of these HIS buildings. With the publication of NBR 15575:2013, this scenario has changed, and the performance evaluation has become an important practice in the business. This article product of a Master's dissertation, will analyze the fulfillment of the criteria and the performance requirements for two case studies - namely, condominiums built within the Program My House My Life in the city of Sorocaba/SP, between the years of 2009 and 2015 - based on NBR 15575 regulations. Therefore, part of our methodology will take as foundation the Post-Occupancy Assessment (POA), developed in the project entitled "Development of methods and methodologies for evaluating the performance of innovative technologies under the National System of Technical Assessment". It is aimed, thus, to create design and construction parameters for future HIS projects in the city of Sorocaba, having the performance as a main parameter of quality and user satisfaction.
\end{abstract}

Keywords: POA, Performance, Housing, HIS.

MARTINS, N. C.; OLIVEIRA, F. L. de. Avaliação do desempenho de edifícios verticais de HIS na cidade de Sorocaba-SP. In: SIMPÓSIO BRASILEIRO DE QUALIDADE DO PROJETO NO AMBIENTE CONSTRUÍDO, 6., 2019, Uberlândia. Anais... Uberlândia: PPGAU/FAUeD/UFU, 2019. p. 1101-1111. DOI https://doi.org/10.14393/sbqp19100. 


\section{INTRODUÇÃO}

Com a divulgação do Estudo de Mercado de Sorocaba - SP (2015), realizado pelo Departamento de Economia e Estatística do Secovi, foi publicado que entre outubro de 2012 e setembro de 2015 foram lançadas 16.417 unidades verticais na cidade. O segmento líder de lançamentos e vendas foi 0 apartamento de dois dormitórios, com cerca de $60,3 \%$ do total de empreendimentos, mostrando, assim, forte aderência do produto ao mercado consumidor. Além disso, a tipologia com maior incidência nesses projetos de HIS foi a planta "tipo H" em edifícios verticais.

No Brasil, a NBR 15575:2013 ("Edificações Habitacionais Desempenho") constituiu-se no principal documento normativo voltado ao desempenho de edificações habitacionais baseado na satisfação do usuário. A obrigatoriedade da Norma de Desempenho em projetos de HIS causou significativas mudanças no mercado da construção civil, forçando as construtoras, escritórios de arquitetura e engenharia e gerentes de obras a incorporar, gradativamente, a Norma em seus projetos.

Para garantir a qualidade do projeto e a satisfação do usuário, a APO pode ser um método eficaz a ser aplicado por diagnosticar como positivo ou negativo o desempenho em uso da edificação pelo ponto de vista de especialistas e usuários, além de ser uma técnica de mensuração do atendimento de exigências normativas.

Pelo exposto, o artigo apresentará um resumo dos resultados obtidos na avaliação de desempenho aplicada por meio de instrumentos baseados metodologia de APO, em dois condomínios verticais de HIS com planta "tipo H" construídos entre 2014 e 2015 no PMCMV na cidade de Sorocaba - SP.

\section{MÉTODOS E TÉCNICAS}

Para avaliação dos estudos de caso analisados utilizou-se um conjunto de procedimentos metodológicos desenvolvidos na pesquisa intitulada: "Desenvolvimento de Procedimentos e Manual para Avaliação de Desempenho de Sistemas Construtivos Inovadores"1, com o apoio da Financiadora de Estudos e Projetos do governo brasileiro e a participação de pesquisadores da FAU-USP e IAU-USP, onde se aplicam os conceitos da APO como mecanismo de inclusão da percepção e da satisfação do usuário na gestão da qualidade do processo de projeto. Embora os procedimentos metodológicos empregados tenham sido criados para sistemas construtivos inovadores, os autores afirmam que também podem ser usados em sistemas construtivos convencionais.

Esses procedimentos metodológicos têm como objetivo verificar o atendimento das exigências de desempenho dos usuários, norteadas principalmente pela NBR 15575:2013, que aborda requisitos e critérios mínimos para produção de edificações residenciais.

Para orientar os profissionais que possam aplicar essa avaliação, a pesquisa criou um manual intitulado de: "Manual de Aplicação de Procedimentos de

\footnotetext{
1 Publicada em uma edição da ANTAC em 2015 um capítulo intitulado: "Procedimentos para a avaliação de desempenho de sistemas construtivos inovadores em uso com vistas ao atendimento à NBR 15575:2013" onde os autores descrevem os procedimentos metodológicos da pesquisa.
} 
Avaliação de Desempenho e de Manutenibilidade". Esse documento tem como objetivo explicar para que serve cada instrumento, a forma que cada um deles deve ser aplicado, o que é preciso para avaliar os temas abordados, quais os materiais e equipamentos devem ser utilizados e como deve ser realizada a análise final dos dados obtidos.

Segundo Ono et al. (2015b), a principal diretriz que permeou o desenvolvimento desse procedimento metodológico, "foi a obtenção de instrumentos eficazes, porém de aplicação rápida e de baixo custo". Considerando-se os métodos e as técnicas da APO, inicialmente foram estabelecidos os tipos de instrumentos a serem utilizados na coleta de dados (Ibidem p. 28), que conta com um conjunto de quatro instrumentos, conforme Figura 1:

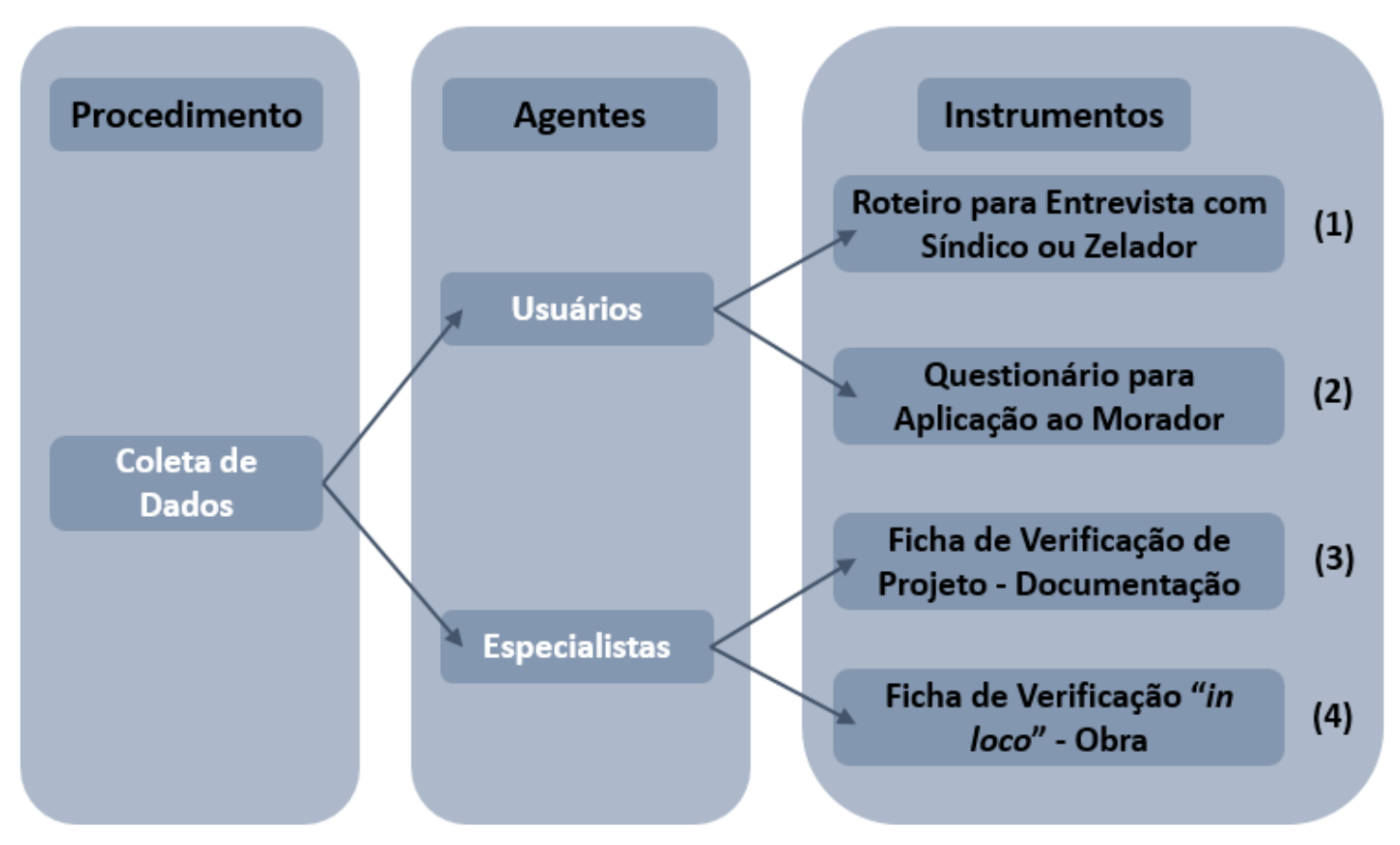

Figura 1 - Estrutura dos Procedimentos de Avaliação e seus Instrumentos Fonte: ONO et. al., (2015b)

Observa-se, por esta figura, que o procedimento é dividido em dois agentes, sendo os usuários e os especialistas e, para cada agente, dois instrumentos são aplicados.

Deve-se destacar que os instrumentos (1) e (3) poderão ser aplicados précampo, ou seja, não necessariamente precisam ser realizados no local dos condomínios analisados. Além disso, é preferível que sejam aplicados antes dos instrumentos (2) e (4) (aplicados em campo), pois "as informações obtidas podem ser úteis na detecção ou identificação de inconformidades na obra" (ONO et. al., 2015b, p. 32) tendo um papel importante na complementação das informações.

Para melhor compreensão da aplicação dos instrumentos, os mesmos serão descritos de forma sucinta, a seguir: 


\subsection{Roteiro para Entrevista com o Síndico}

Esse instrumento tem como objetivo obter informações sobre o desempenho em uso do sistema construtivo dos estudos de caso. Em caso do empreendimento apresentar alguma forma de administração condominial, esta deverá ser mediante o responsável legal (síndico), pois ele é considerado como o detentor de informações relevantes do panorama sobre 0 desempenho em uso dos estudos de caso.

\subsection{Questionário para Aplicação ao Morador}

Esse instrumento tem como objetivo obter dados por meio do usuário dos estudos de caso, quanto à sua compreensão e avaliação do desempenho em uso das unidades habitacionais. Os usuários devem estar conscientes da importância de sua participação na pesquisa, pois são eles quem usufruem da edificação e podem apontar informações que muitas vezes passam despercebidas em visita técnica. A aplicação deve ser feita mediante o Termo de Consentimento Livre e Esclarecido (TCLE), documento detentor de todas as informações da pesquisa e pesquisador. Ao final, o TCLE deve ser assinado pelo usuário, autorizando o uso das informações.

Os questionários estão divididos em três grupos, onde o primeiro caracteriza o perfil do usuário, o segundo aborda a interface do usuário com sua moradia e o terceiro a interface do usuário com o sistema construtivo dos estudos de caso.

Antes de aplicar os questionários, é necessário saber qual o número total das UHs dos estudos de caso, para depois definir o número da amostra a ser coletada. Além disso, para a realização dessa etapa, deve-se estudar uma logística de aplicação e recebimento das respostas, que podem ser aplicados pessoalmente ou remotamente pela internet.

\subsection{Fichas de Verificação}

"As fichas de verificação foram elaboradas para uso pelos técnicos (especialistas) para avaliação do desempenho das edificações" (ONO et al., 2015b, p. 30) e têm como objetivo "observar e registrar os aspectos que interferem na qualidade e segurança da edificação. Para tanto, compõemse de fichas com temas agrupados em oito itens" (Ibidem, p. 30), sendo eles: desempenho acústico; desempenho térmico; desempenho lumínico; funcionalidade; acessibilidade; segurança contra incêndios; segurança no uso; durabilidade, vida útil e desempenho estrutural. São constituídas por dois tipos de instrumentos:

- Ficha de Verificação de Projeto - Documentação: podem ser avaliados a partir da análise da documentação técnica disponível. Ressalta-se que a verificação dos requisitos e critérios segundo a NBR15575:2013, por este instrumento, reflete o desempenho potencial dos componentes analisados, visto que o desempenho real pode ser comprometido pelas características construtivas executadas em obra. Para aplicação desse instrumento considerou-se também o Código de Obras da cidade de Sorocaba - SP (Lei $n^{\circ} 1437$, de 21 de novembro de 1966), pelo qual alguns requisitos tabelados sofreram alterações, prevalecendo a exigência local. 
- Ficha de Verificação "in loco" - Obra: Esse instrumento torna-se importante, pois podem ter sido modificadas algumas soluções projetuais na execução da obra, resultando em alterações na documentação. Antes de aplicar esse instrumento, deve-se aplicar o instrumento (3).

As fichas de verificação seguem o formato apresentado no Quadro 1, onde os requisitos e critérios analisados são aqueles definidos pelas normas da Associação Brasileira de Normas Técnicas (ABNT).

Quadro 1 - Modelo de ficha de verificação

\begin{tabular}{|c|c|c|c|c|c|c|}
\hline \multirow{2}{*}{ No. } & \multirow{2}{*}{$\begin{array}{c}\text { Requisitos e } \\
\text { Critérios }\end{array}$} & \multirow{2}{*}{$\begin{array}{c}\text { Nível de } \\
\text { importância }\end{array}$} & \multicolumn{4}{|c|}{ Nível de atendimento } \\
\cline { 4 - 7 } & & & Atende & $\begin{array}{c}\text { Não } \\
\text { atende }\end{array}$ & $\begin{array}{c}\text { Não se } \\
\text { aplica }\end{array}$ & $\begin{array}{c}\text { Não } \\
\text { verificado }\end{array}$ \\
\hline 01 & $\ldots \ldots \ldots \ldots$. & Obrigatório & $\square$ & $\square$ & $\square$ & $\square$ \\
\hline 02 & $\ldots \ldots \ldots \ldots . .$. & Facultativo & $\square$ & $\square$ & $\square$ & $\square$ \\
\hline
\end{tabular}

Fonte: ONO et. al. (2015a)

Os atendimentos considerados obrigatórios são baseados em exigências mínimas estabelecidas por normativas técnicas, já os atendimentos considerados facultativos são procedimentos recomendados em conformidade com boas práticas de construção e uso que garantem a qualidade projetual. Para a classificação do nível de atendimento foram adotadas as seguintes condições:

- Atende: o requisito da questão foi atendido plenamente;

- Não atende: o objeto da questão foi atendido parcialmente ou não foi atendido;

- Não se aplica: o objeto da questão não existia;

- Não verificado: não houve a verificação do atendimento do objeto por algum motivo.

\section{DESCRIÇÃO DOS ESTUDOS DE CASO}

Foram analisados dois condomínios de edifício de HIS, localizados em Sorocaba nas zonas territoriais Oeste e Norte que apresentaram maiores índices de empreendimentos para o público do PMCMV. Os estudos de caso foram aqui denominados como Condomínios A e B (Figuras 2 e 3).

Os estudos de caso foram entregues pela mesma construtora e apresentaram, nas plantas das UH, algumas semelhanças construtivas. Há padronização de tipo de janelas, portas, louças e metais, as dimensões dos cômodos são aproximadas, exceto as dimensões da circulação interna. Além disso, o sistema construtivo é o mesmo, construídos em Alvenaria Estrutural (EA) de blocos cerâmicos. As diferenças estão na implantação, distribuição dos blocos, acesso à portaria e aos blocos, acessibilidade, sistema elétrico e hidrossanitário, quantidade de apartamentos por andar, de andares e de blocos. 


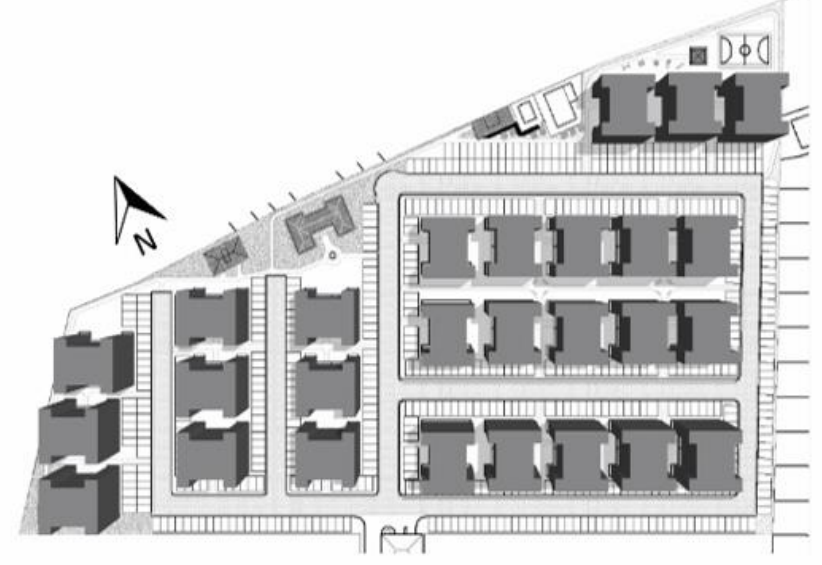

\begin{tabular}{lc}
\multicolumn{2}{c}{ Estudo de caso: Condomínio A } \\
Zona Territorial & Oeste \\
Ano de entrega & 2015 \\
№ de blocos & 27 \\
№ de andares & Térreo +8 \\
№ de apartamento por andar & 2 \\
Total de unidades & 486 \\
Área apartamento & $47,28 \mathrm{~m}^{2}$ \\
№ de apartamento acessivel por bloco & 1
\end{tabular}

Figura 2 - Implantação do Condomínio A -

Fonte: Autoras

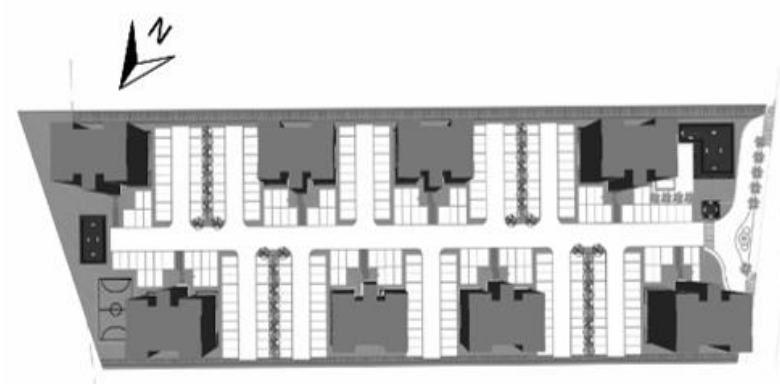

Estudo de caso: Condomínio B

$\begin{array}{lc}\text { Zona Territorial } & \text { Norte } \\ \text { Ano de entrega } & 2014 \\ \mathbf{N} \circ \text { de blocos } & 8 \\ \mathbf{N} \circ \text { de andares } & \text { Térreo +7 } \\ \mathbf{N} \circ \text { de apartamento por andar } & 4 \\ \text { Total de unidades } & 256 \\ \text { Área apartamento } & 50,28 \mathrm{~m}^{2}\end{array}$

№ de apartamento acessível por bloco

Figura 3 - Implantação do Condomínio B -

Fonte: Autoras

\section{RESULTADOS DA APLICAÇÃO DOS INSTRUMENTOS}

Por meio da aplicação dos instrumentos foi possível analisar aspectos técnicos (documentações, vistorias em campo e entrevistas com os responsáveis legais) e fatores que envolvem as opiniões dos usuários e, consequentemente, seu nível de satisfação.

\subsection{Roteiro para Entrevista com o Síndico}

Constatou-se que independentemente de serem dois condomínios distintos, a maioria das problemáticas relatadas pelos síndicos são: problemas elétricos, umidade/infiltração, falta de acessibilidade das instalações para realizar manutenções, reformas nas áreas de lazer que não atendiam à demanda dos usuários e desconforto acústico nos apartamentos.

Segundo os síndicos, a falta de clareza do Manual de Uso, Operação e Manutenção, faz com que muitos moradores (leigos) contratem empresas especializadas para realizar determinada manutenção, ou simplesmente não a fazem. 


\subsection{Questionário para Aplicação ao Morador}

A maioria dos respondentes de ambos estudos de caso são os responsáveis pela moradia, proprietários e/ou primeiros moradores e residem em seus respectivos apartamentos por um tempo superior há três anos, sendo a composição familiar de jovens casais, com faixa etária entre 30 a 40 anos, sem filhos.

No estudo de caso Condomínio $\mathbf{A}$, observou-se que o gênero predominante dos respondentes era feminino, sendo o grau de escolaridade o Ensino Médio completo e a média de gastos mensais (conta de luz, taxa do condomínio, telefonia, internet e TV por assinatura) chega até o valor de $R \$ 200,00$ reais, no Condomínio B o gênero masculino predominou, com grau de escolaridade de Ensino Superior completo e média de gastos (conta de luz, taxa do condomínio, telefonia, internet e TV por assinatura) superior a $R \$ 101,00$ reais.

Quanto aos aspectos de segurança no uso, observou-se que, mesmo representando uma minoria, alguns respondentes relataram a ocorrência de acidentes domésticos, tais como quedas e escorregões, atribuídos ao tipo de piso entregue pela construtora nas áreas molhadas e molháveis. Além disso, observou-se que no Condomínio A, 6,7\% dos respondentes informaram que ocorreram princípios de incêndio nas UHs. Esse fato está relacionado à ineficiência do funcionamento das instalações elétricas que, não suportando carga superior a que foi projetada, causou curtos circuitos de tomadas e queimas de equipamentos elétricos.

Por não possuírem conhecimento pleno sobre o sistema construtivo empregado nos edifícios, alguns moradores relataram dificuldade para a realização de modificações (flexibilidade).

Observou-se também que alterações recorrentes ocorreram (minoria dos respondentes), dentre elas a troca do revestimento original dos banheiros, o rebaixamento do forro com placas de gesso, a troca de fiação elétrica e a colocação de novos pontos de tomada e luz. Quanto ao tamanho de alguns cômodos das UHs, a maioria dos respondentes considerou insatisfatório a área de serviço, banheiro e cozinha.

As paredes de vedação de blocos cerâmicos (14x19x29cm), revestidas com argamassa $(1 \mathrm{~cm})$ não atendem ao nível mínimo de desempenho $(45 \mathrm{~dB}), 0$ que foi comprovado pela porcentagem majoritária dos moradores que afirmaram sentir incômodo com ruídos do apartamento vizinho $172 \%$ no Condomínio A e 77,3\% no Condomínio B). O mesmo acontece com o barulho das instalações hidráulicas, onde a porcentagem dos moradores que se incomodam também é maioria (Condomínio A $80 \%$ e no Condomínio B 59,1\%).

Verificou-se que a maioria dos respondentes recebeu o Manual de Uso, Operação e Manutenção, porém menos da metade o leram. Dos quais leram, $57,1 \%$ (Condomínio A) e 61,5\% (Condomínio B) alegaram não conseguir realizar os procedimentos de manutenção descritos.

\subsection{Ficha de Verificação de Projeto - Documentação}

Serão apresentados de forma concisa os resultados obtidos, por tema, de maior representatividade de não atendimento, sendo: 
- Desempenho Acústico: atribui-se os requisitos "não atendidos" (25\%), nos dois estudos de caso, ao nível mínimo de isolamento acústico (45dB) entre as paredes internas das unidades.

- Desempenho Térmico: no Condomínio A e $\mathbf{B}$, os requisitos "não atendidos" (60\%) referem-se à Capacidade Térmica das paredes da fachada e às áreas de aberturas (janelas), que não consideraram as exigências mínimas do Código de Obras² da cidade de Sorocaba.

- Funcionalidade: os requisitos referem-se às dimensões mínimas de circulação dos dormitórios, sala de estar e jantar, banheiro, cozinha, área de serviço, altura de pé direito $(>2,5 \mathrm{~m})$, número de pontos de tomadas e telefone nas unidades e o distanciamento entre eles. Os estudos de caso foram considerados "não atende" no que se refere aos requisitos de distanciamento entre os pontos de tomada $(27 \%$ no Condomínio A) e aos critérios sobre menor dimensão dos cômodos (19\% no Condomínio B).

- Acessibilidade: no Condomínio A, os requisitos "não atendidos" (29\%) foram sobre o nível das soleiras $(<5 \mathrm{~mm})$, largura dos vãos das portas e dimensão mínima dos banheiros; e no Condomínio B $(41,5 \%)$ referem-se à largura dos vãos de passagem do acesso aos edifícios e ao nível das soleiras.

- Segurança contra Incêndio: os requisitos "não atendidos" no Condomínio A (11\%) foram sobre proteção dos dutos de gás externos e no Condomínio B (6\%) referem-se a altura dos acionadores. Ressalta-se que os critérios de aprovação do Auto de Vistoria do Corpo de Bombeiros (AVCB) foram atendidos em sua plenitude em ambos estudos de caso.

- Durabilidade, Vida Útil e Desempenho Estrutural: os requisitos "não atendidos" (56\%), nos estudos de caso, referem-se unicamente às informações não contidas nos projetos e no manual de uso, operação e manutenção do edifício, e não à capacidade portante da estrutura. O manual não apresentou informações importantes sobre o sistema construtivo, vida útil e manutenção das unidades; os projetos apresentavam insuficiência de informações técnicas e representações gráficas sobre as características construtivas do sistema construtivo.

\subsection{Ficha de Verificação "in loco" - Obra}

As verificações de áreas internas, externas aos blocos e halls foram realizadas no interior dos apartamentos onde foram verificados aspectos sobre:

- Desempenho Lumínico: os cômodos classificados na categoria "não atende" (16\% no Condomínio A e 9\% no Condomínio B), foram aqueles cuja UH possuía insulfim nas janelas devido a incidência direta do sol (informação dos próprios usuários), falta de privacidade (em apartamento do térreo), além de cortinas e paredes internas pintadas

\footnotetext{
2 Considerando que a Norma de Desempenho sugere o uso das especificações da legislação local do projeto quando essas forem mais restritivas, o Código de Obras da cidade de Sorocaba (Lei $n^{\circ} 1437$, de 21 de novembro de 1966, art.20, alínea "a"), exige uma área de abertura para janelas de, no mínimo, 1/8 da área do piso, ou seja, 12,5\%, o que não foi observado nos estudos de caso.
} 
com cores escuras e roupas no varal. Porém, considerando a ocorrência dessas obstruções, os resultados de nível de iluminância geral para iluminação natural apresentaram valores próximos ao estabelecido por norma (60 lux).

- Acessibilidade: o requisito a ser vistoriado trata-se da largura do vão livre das portas das UH. $100 \%$ das UH, dos dois estudos de caso, foram considerados na categoria "não atende", até mesmo as unidades consideradas "acessíveis" no Condomínio A. Nos halls, nenhum dos blocos atendeu ao requisito em sua totalidade, pois os vãos de abertura e as portas apresentaram largura superior a $0,80 \mathrm{~m}$, mas as soleiras não possuíam desnível inferior a $5 \mathrm{~mm}$. A mesma situação foi observada nas áreas externas dos blocos.

- Segurança contra incêndio: os requisitos referentes ao número de pontos de tomada e as boas condições de funcionamento dos disjuntores nas UH foram os que tiveram maiores incidência na categoria "não atende" (45\% no Condomínio A e 35\% no Condomínio B), pois, além do que os moradores relataram, pôde-se observar que o número de tomadas não é o suficiente para atender as necessidades dos usuários, principalmente na sala de estar/ jantar e cozinha, pois muitos moradores precisam utilizar "tês/ benjamins" e "réguas" para ligar os equipamentos eletrônicos, além de estabilizadores. Quanto aos halls, observou-se que o Condomínio A "não atende" (100\%) ao requisito sobre altura adequada do corrimão $(0,92 \mathrm{~m})$. Nos estudos de caso (23,6\% no Condomínio A e $21,5 \%$ no Condomínio B), em alguns blocos os hidrantes, extintores, cabines de força, centrais de gás e alarmes não estavam bem sinalizados. Além disso, alguns extintores apresentaram a alça de manuseio com altura superior ao estabelecido (no máximo, a $1,60 \mathrm{~m}$ do piso acabado e a parte inferior acima de $0,10 \mathrm{~m}$ do piso).

- Segurança no uso: nos requisitos sobre acabamento de pisos internos da área do hall todos (100\%) os blocos dos dois estudos de caso foram considerados na categoria "não atende" por terem desníveis superior a $5 \mathrm{~mm}$. O Condomínio A foi considerado na categoria "não atende" (100\%) a respeito do requisito de dimensões de pisos e espelhos constantes em toda a escada e a distância entre os perfis do gradil $(>0,11 \mathrm{~m})$.

- Durabilidade, Vida útil e Desempenho estrutural: em algumas unidades, de ambos os condomínios $(20,6 \%$ no Condomínio A e $21,8 \%$ no Condomínio B), foi possível verificar outras incidências, como: ralo com mal cheiro; o caimento do piso do box não escoa a água para o ralo; revestimentos dos banheiros com fissuras; fissuras no forro de gesso; falta de integridade do rejunte das peças cerâmicas e do vaso sanitário. Nos dois condomínios (75\%), observou-se a incidência de fissuras nas áreas dos halls de entrada de todos os blocos, sinais de umidade na base das paredes na área externa dos blocos, infiltração e falhas da impermeabilização exposta nas áreas molhadas externas - piscinas, reservatórios, coberturas e jardins - $141,1 \%$ no Condomínio A e $45 \%$ no Condomínio B) e também, não foram observados sinalização (placa) informando o sistema construtivo da edificação e que qualquer modificação deve ser consultado um profissional da área. 


\section{ANÁLISE DOS RESULTADOS}

Por meio da aplicação dos instrumentos nos estudos de caso, foi possível analisar aspectos técnicos (documentações, vistorias em campo e entrevistas com os responsáveis legais) e fatores que envolvem as opiniões dos usuários e, consequentemente, seu nível de satisfação.

Em relação ao instrumento "Entrevista com o Síndico", os responsáveis legais (síndicos) relataram as mesmas reclamações recorrentes dos moradores, sendo problemas causados pela ineficiência da impermeabilização (tais como umidade e infiltração), e essas manifestações patológicas também foram verificadas em campo. Considerando essas incidências, a estanqueidade à água de ambientes deve ter um projeto específico, que detalhe os produtos e a forma de execução das técnicas de aplicação dos sistemas ideais de impermeabilização para cada caso.

É evidente, em dois instrumentos aplicados (Questionário ao Morador e Ficha de Verificação de Projeto - Documentação), que o conforto acústico em cômodos adjacentes e apartamentos vizinhos estão em desconformidade. 0 primeiro instrumento apresentou uma porcentagem significativa dos respondentes descontentes, enquanto o segundo constatou que o sistema construtivo não atende ao mínimo de Índice de Redução Sonora Ponderado $\left(R_{w}\right)$ estabelecido pela Norma de Desempenho (de $45 \mathrm{~dB}$ ).

Já no tema conforto térmico, os respondentes sentem mais desconforto no período mais quente do ano. No período de frio, a maioria classifica como confortável/agradável o apartamento como um todo, isso se dá por uma das características da planta "tipo H", onde sempre haverá face para o sol da manhã e para o sol da tarde (confortável para o período frio e desconfortável para o período quente).

Quanto aos resultados do instrumento "Ficha de Verificação in loco - Obra", observou-se que algumas das especificações de projeto não haviam sido executadas. No item "Acessibilidade", na planta de implantação do Condomínio B, existia uma rampa de acesso (P.C.R. e P.M.R.) da rua para a portaria, o que não foi constatado in loco. Verificou-se que no lugar da rampa havia uma escada.

\section{CONSIDERAÇÕES FINAIS}

O procedimento metodológico aplicado foi eficiente na indicação de informações relevantes para retroalimentar o processo de projeto, por meio da identificação dos sucessos e das falhas e apontando modificações para o atendimento da satisfação do usuário.

Além disso, esta avaliação consistiu em verificar se as condições do ambiente em uso são satisfatórias quanto ao desempenho do sistema construtivo do ponto de vista dos seus usuários e pode também ser um instrumento de garantia de qualidade para construtoras, incorporadoras, financiadoras e prefeituras no sentido de identificar melhorias significativas, servindo como parâmetro para um resultado cada vez melhor.

A problemática sobre a qualidade construtiva das HIS vem se acumulando há décadas e várias pesquisas, ao longo do tempo, foram desenvolvidas na tentativa de minimizar as consequências que envolvem as condições de 
precariedade devido à infraestrutura, ou mesmo, à própria questão da construção da moradia.

Os resultados desta pesquisa apontaram vários aspectos de melhorias que podem ser aplicados facilmente em futuros projetos. Porém, se não forem colocados em prática, se resumirão a informações sobre os erros e acertos necessários para garantir o desempenho em uso da edificação. Faz-se necessário então, maior sinergia entre a academia e o setor produtivo da construção civil, no sentido de proporcionar avanços na qualidade arquitetônica e construtiva das moradias que estão sendo oferecidas aos usuários nos empreendimentos sociais.

\section{REFERÊNCIAS}

ASSOCIAÇÃO BRASILEIRA DE NORMAS TÉCNICAS (ABNT). NBR-15575:2013.

Edificações Habitacionais - Desempenho. Rio de Janeiro, 2013.

ONO, R., ORNSTEIN, S., OLIVEIRA, F., GALVÃO, W. Avaliação Pós-Ocupação:

Pré-teste de instrumentos para verificação do desempenho de empreendimentos habitacionais em sistemas construtivos inovadores. Gestão e Tecnologia de Projetos v. 10, n. 1, p. jan./jun. 2015a.

ONO, R.; OLIVEIRA, F. L.; ORNSTEIN, S. W.; GALVÃO, W. J. F.; GHOUBAR, K. Procedimentos para a avaliação de desempenho de sistemas construtivos inovadores em uso com vistas ao atendimento à NBR 15575:2013. In: FABRICIO, M. M.; ONO, R. (Org.). Avaliação de Desempenho de Tecnologias Construtivas Inovadoras. 1. ed. Porto Alegre: ANTAC, 2015b, v., p. 27-40. DOl: http://dx.doi.org/10.4322/978- 85-89478-42-7-04.

SECOVI 2015. Secovi- SP divulga Estudo de Mercado de Sorocaba. Disponível em: <secovi.com.br/downloads/pesquisas-e-indices/estudos-dointerior/Sorocaba/estudo-do-mercado-imobiliario-de-sorocaba-2015.pdf>. Acesso em: 29 mai. 2019. 